\title{
Alternative of Visual Based Learning (VBL) Method Based on Short Duration Video for The Instrumental Chemistry Subject in Chemistry Department
}

\author{
Riyanto $^{a, *}$, Beta WulanFebriana ${ }^{b}$ \\ ${ }^{a}$ Department of Chemistry, Islamic University of Indonesia \\ ${ }^{b}$ Department of Chemistry Education Department, Islamic University of Indonesia \\ ${ }^{*}$ Corresponding author: riyanto@uii.ac.id
}

\begin{abstract}
There had been done a study of Visual Based Learning (VBL) method based on Short Duration Video for Instrumental Chemicals Subject in Chemistry Study Program of Mathematics and Natural Sciences Faculty (MNSF), Islamic University of Indonesia (Universitas Islam Indonesia-UII). VBL method is carried out by creating a short duration video about an instrument according to the syllabus of instrument 1 subject such as AAS, UV-Vis Spectrophotometer, FTIR, GC-MS, and CV. In order to determine the effect of VBL method using, an analysis of scores obtained between the experimental class and the control class is used. To determine the effect of VBL on psychomotor ability is done by observing directly when students do an experiment or practicum. The influence of VBL method application on student motivation was studied by using questionnaire. The results pointed out that the data of both samples (both classes) is homogeneous. T-test results: Two-Sample Assuming Equal Variances showed that there is a significant difference in the final scores mean between the experimental class and the control class. Based on the mean score it indicates that the VBL method is better while compared to the learning method without VBL. VBL method has a significant effect on students motivation and psychomotor ability when it is viewed from observation of practicum and the score of practicum. The conclusion is that the VBL method is able to increase students' motivation and psychomotor ability in the Instrumental Chemistry subject.
\end{abstract}

Keywords: Learning, video, chemistry, instrumental

\section{INTRODUCTION}

During the time, learning method used in the Instrumental Chemistry subject has been using lecture method and group presentation (discussion). This subject has a very strategic objective to equip graduates. Fieldwork of Chemistry Study Program alumni in industries is in the field of quality control (QC) and quality assurance (QA). An ability to be mastered by a QC personnel is able to understand the instrumentation used, able to operate the instrumentation, able to solve the problem of instrumentation or troubleshooting and able to process the data of analysis or testing results. Therefore, the mastery of instrumentation chemistry is needed by the graduates of Chemistry Study Program.

Some companies open job vacancy as a QC personnel with requirements that are able to maintain and operate laboratory equipments such as GC, GC-MS, HPLC, spectrophotometer, AAS, auto lab and etc. Due to the importance of the instrumental course, the level of achievement and mastery of the subject matter must be maximum. During this time lecturers delivered the course in the class only using lecture method and group discussion. Discussion method can increase the interaction between students and a lecturer (Figure 1B).

The learning methods used today are lectures and group discussions. Both methods can not create the spirit of learning on students because the students only memorize the lecture materials to obtain good score. The method causes the students to be inactive. Lecture method only results in one-way interaction that is a lecturer to students.

Based on the data of Instrumental Chemistry scores in the previous academic year (even semester $2014 / 2015$ ) it is found that the scores of the course $\geq B$ is $75 \%$. Scores of the Instrumental Chemistry 
subject less than B is $25 \%$. It shows that the level of achievement is still low. Because of the importance of this course, the graduation rate or score $\geq B$ should be increased.

Implementation of this learning methods caused a less satisfied attitude to the students, especially for subjects concerning to the instrumental materials in Chemistry Study Program. Important instruments not yet owned by Chemistry Study Program or UII are ICP-MS, XRF, XRD, XPS, SEM-EDX, LC-MS, TGA, DTA and DCS. Students have never seen the form or shape of the tools. This is harmful because in the world of work students must be able to operate these tools. Instrumentations that are not owned yet by the Chemistry Study Program and UII are very expensive with the price range between 1 to 5 billion. To overcome this, it is necessary to propose a learning method using Visual Based Learning (VBL).

(A)

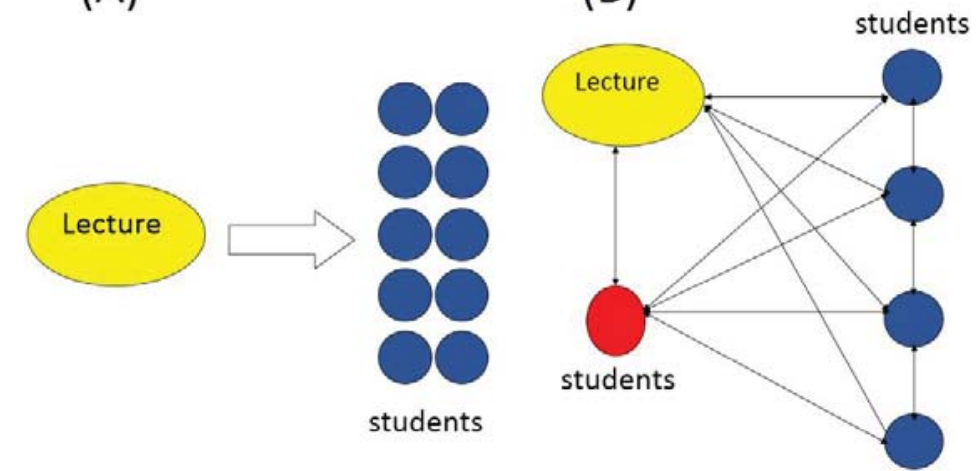

FIGURE 1. Comparison of the number of interactions between the lecture method $(A)$ and discussion method as well as eLearning (B)

Learning method in Figure 1A. onny assumes the students as spectators and the lecturer as a player. Students are only as subjects of learning rather than objects. This causes the method to produce inactive students, less communication skill and lower level analysis of students. Lecture and discussion methods can not equip and enhance students' motivation to study and love chemistry. Besides the method of lectures (regular lectures) only led to a little material that can be absorbed by students. Seng stated that the most effective learning method is teaching and discussing[1]. The method of delivering material to others will cause the subject matter absorbed by the students reach $80 \%$, through the discussion method reaches $50 \%$, while the lecture method is only $5 \%$.

Motivation is one indicator of sucess in the learning process. If students can be motivated to learn, how a difficult of a subject matter, students will still be happy in learning. Motivation is the power or energy drives a person's behavior to active[2]. Motivation is very important to spur nest activities. Motivation has an enormous influence on learning because it is able to generate energy, direct people to specific goals, encourage people to start an activity and survive in doing an activity, learn more meaningfully and practice it [3]. The growing of student's motivation will be used as a learning capital for other subjects and proceed to the next semester. By applying this method it is expected that students are more focus to study chemistry so there is no intention to move on another study program.

During the time the learning method in the instrumental chemistry subject has been using lecture method with power point aids. Powerpoint has a weakness that is only delivering one-dimensional images (Figure 4), cannot describe the real situation, and the students are less motivated. Instrumental chemistry subject should be delivered in accordance with students work. The Instrumental Chemistry subject is not appropriate to be delivered with lectures, group discussions, power point aids, but it should be augmented with a video learning medium or short duration film of 10-15 minutes. Therefore, using video-based or film-based learning media is appropriate for teaching Instrumental Chemistry subject.

The problem encountered by the current learning method viewed from the learning result achieved by the students is that the method would result in inactive students, less communication skill and low level of students analysis. The lecture method can not equip and increase students' motivation to study and love Chemistry. In addition to the method of lectures (regular lectures), there is only a little material that can be absorbed by students that are about $5 \%$.

Different learning methods will give effect to students with different results as well. The lecture learning method will have the least effect or the material absorbed by the students is least compared to other 
methods. Pyramid of the learning methods and the average of material absorbed by the students is shown in Figure 2.

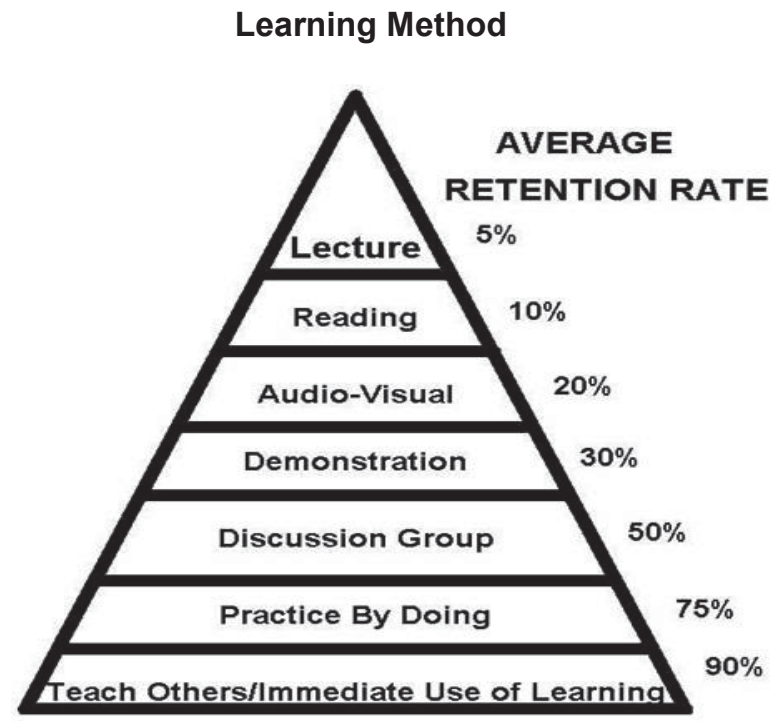

FIGURE 2. Differences in learning methods and the average retention rate ${ }^{1}$

Almost of the subject matters in Chemistry Study Program are abstract and rich of theories that the application is not visible. The teaching method that is presented in current time mostly embraces the old way that is the lecturer deliver the materials as the puppeteer keeps to tell until the time is up. This kind of learning system causes students to be unmotivated in learning and there is no desire to search for supporting theories from various references. Students become inactive. Students should become subjects of learning that can determine their own learning needs[4,5]. In this research, it is proposed that learning method conveys material in form of video or film for 10-15 minutes for each subject or instrument. Lecturer emphasizes the application of theories learned in the form of video, then explains the definition and supporting theories. If the students already know the benefits of learning a science then they will remain motivated. The advantages of this method in addition to motivate students, abstract courses will look more concrete without practicum. Motivation is one indicator of success in the learning process[6]. If students can be motivated to learn, how a difficult any subject matter, then students will still be happy in learning. Motivation is the power or energy drives a person's behavior to move [2]. Motivation at the beginning of the lesson is very important to spur next activities. Motivation has an enormous influence on learning because it is able to generate energy, direct people to specific goals, encourage people to start activities and survive in an activity, learn more meaningfully and practice it [3].

In this research, it is proposed the learning method of instrumental chemistry by combining the lecture and discussion method and visual-based learning (VBL) method. VBL method based on 10-15 minutes video is necessary to apply because instrumentation subject involves instrumentation in an industry such as AAS, spectrophotometer, GC, GC-MC, HPLC, FTIR, XRD, SEM-EDX, ICP-MS, TGA, DTA, DSC, and AUTOLAB. If the subject matter of the instrument is delivered with an abstract lecture, the students are difficult to imagine the shape of the tools, the way of work and the result of the analysis. Therefore, instrumental chemistry subject matter needs to be delivered via video or known as visual-based learning.

Based on the results of that study, the researchers proposed the use of visual-based learning (VBL) method based on the short-duration video for the instrumental chemistry subject matter.

\section{LITERATURE REVIEW}

According to Henriksen and Neppl [7], a video or better known as a film can simply be defined as a story that is told to audiences through a series of moving pictures. Film or movie is the images in frames where the frame by frame is projected through the lens of projector mechanically so that on the screen the image appears to be alive. The function of $\mathrm{f}$ ilm in the learning process is related to three things that 
are for cognitive purposes, for psychomotor purposes, and for affective purposes. In relation to cognitive purposes, a film can be used to:

1. Teach return introduction or differentiation of relevant motion stimulation, such as the speed of moving objects, and so on.

2. Teach rules and principles. Movie can also show a row of verbal expressions, such as on motionless images and printed media. For example to teach the meaning of sincerity, fortitude, and so forth.

3. Shows examples of appearance models, especially in situations that show human interaction.

In relation to the psychomotor objectives, film is used to show examples of motion skills. This media can also slow or accelerate movement, teaches how to use a tool, how to do an action, etc. In addition, the film can also provide students with visual delayed feedback to demonstrate their level of ability to perform motion skills, after sometime later [7].

In relation to affective goals, a film can affect one's emotions and attitudes, that is by using various means and effects. It is a suitable tool for demonstrating affective information, either through optical effects or through relevant visual imagery. Some of the advantages of film as a medium in education according to Henriksen and Neppl [7]are:

1. Very good to explain a process. For example the process of creation of the universe.

2. Can re-display the past and re-present historical events of the past.

3. Can overcome the limitations of distance and time.

4. Can attract children's attention.

5. More realistic, repeatable, can be stopped, and so on as needed. Abstract things become clear.

6. Can overcome the limitations of sensory power (sight).

7. Can stimulate or motivate children's activities.

8. Can be used in large and small groups.

9. Can convey the sound of an expert as well as look at his/her appearance.

10. Very strongly affects a person's emotions.

Some researchers argued the benefits of visual-based learning methods. Hou [8]and Lei [9] stated that the method by using video can improve the cognitive, affective and verbal skills of learners. Saiman [10] said that the impact of learning with video on students with autism is very good. Video-based learning method will drill students to think clearly what is happening in industry and laboratory. This will increase students motivation as presented by Peredo [11] and Merchant [12]. Video learning can convey contextually materials (context based sciences) that impact student motivation such as the study results of Kuhn and Müller [13], Kay and Kletskin [14]. The video-learning method is well suited for improving interactive classroom atmosphere, according to the research by Marsh [15],Henriksen and Neppl [7]. The scheme of learning method with visual-based learning (VBL) is shown in Figure 3.

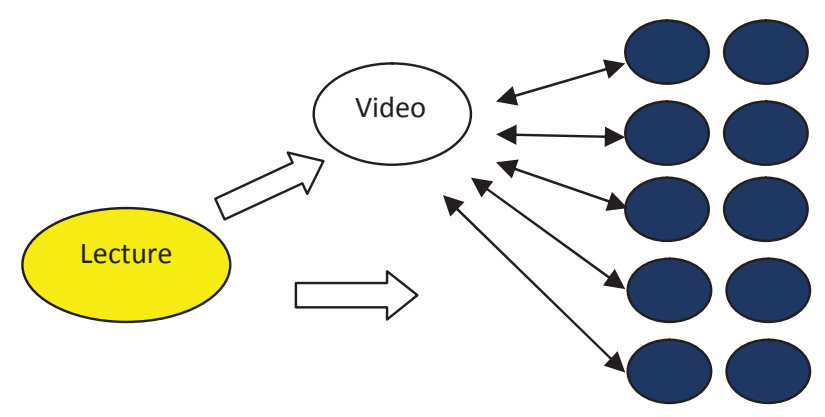

Students

FIGURE 3. Scheme of learning method with visual-based learning (VBL) on instrumental chemistry course

There is a close relationship between the visual-based learning and visual thinking that is a learning style in which learners are better to understand and retain information when the ideas, words, and concepts are associated with an image. Results of the study showed that the majority of students need to see information to learn it. Some visual learning strategies include video, graphics, diagrams, mind mapping. Visual learning helps students clarify the students' minds. Students look at how ideas are 
connected and are aware of how information can be grouped and organized. By the visual learning, new concepts are more thorough and easy to understand when it relates to previous knowledge [9].

Visual learning helps students organize and analyze information. Students can use diagrams and plots to display large amounts of information in a way that is easy to understand and helps to reveal the relationships and patterns. Visual learning helps students integrate new knowledge. According to study, students are more likely to remember information when they learn visually and verbally. Visual learning helps students think critically [12].

According to Kay and Kletskin [14],visual thinking and learning make use the way of graphics in working with ideas and presenting information. Researchers in educational theory and cognitive psychology said that visual learning is among the best methods to teach students of all ages the way of thinking and the way of learning. Visual learning strategies such as video, graphics, diagrams. This strategy helps students or all ages both to manage learning goals and achieve academic success. As students are required to evaluate and interpret information from various sources, incorporate new knowledge with what they have learned, and improve their writing and critical thinking skills, visual learning tools help students meet the demands. Coupled with brain capacity for images, visual learning strategies help students better understand and store information [11].

Visual-based learning is widely used in companies that are by using information technology that is creating and managing digital information and achieve the right information, the image is the most common way of communicating and used by companies. Images and videos can be re-accessed and effectively demonstrate structure, relationships, and patterns ${ }^{7}$. A structured digital visual learning method allows students to discover and learn visual exploration. The impact is amazing, students can better understand the structure, relationships, and contexts of complicated topics and achieve faster recall and retention [8].

\section{RESEARCH METHODS}

An example of the scenario in creating a learning video with the AAS theme is shown in Table 1.

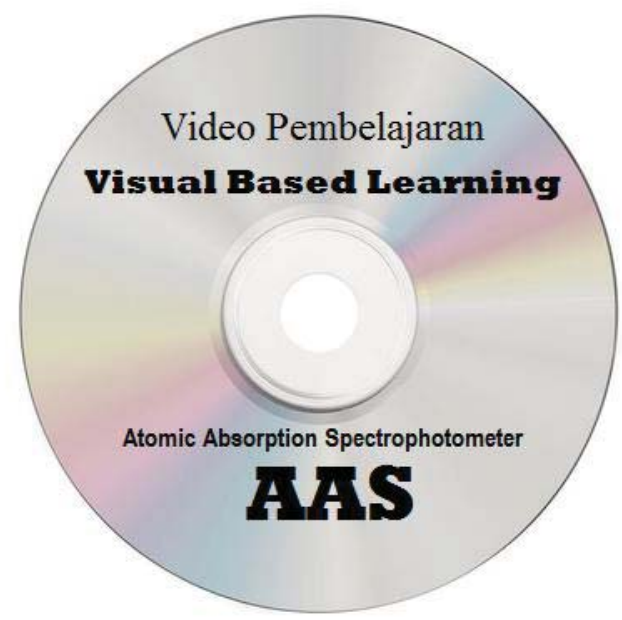

FIGURE 4. Example of video cover for Visual Based Learning

TABLE 1. Scenario Example in creating AAS learning video

\begin{tabular}{lcl}
\hline $\begin{array}{l}\text { Theme } \\
\text { Cast }\end{array}$ & $:$ & $\begin{array}{l}\text { Atomic Absorption Spectrophotometer (AAS) } \\
\text { Subject }\end{array}$ \\
$\begin{array}{l}\text { Location } \\
\text { Impression design }\end{array}$ & $:$ & $\begin{array}{l}\text { Instrument of AAS Perkin Elmer P } 1500 \\
\text { Ull Integrated Instrumentation Laboratory } \\
\text { Ull Integrated Laboratory Building, } 3^{\text {rd }} \text { Floor, South Wing } \\
15 \text { minutes }\end{array}$ \\
\hline $\begin{array}{l}\text { Segment Sharing } \\
\text { Introduction }\end{array}$ & $:$ & $\begin{array}{l}5 \text { segments and 1 introduction } \\
\text { Explanation of instrument name, brand, usability, year of manufacture and calibration }\end{array}$ \\
\hline
\end{tabular}




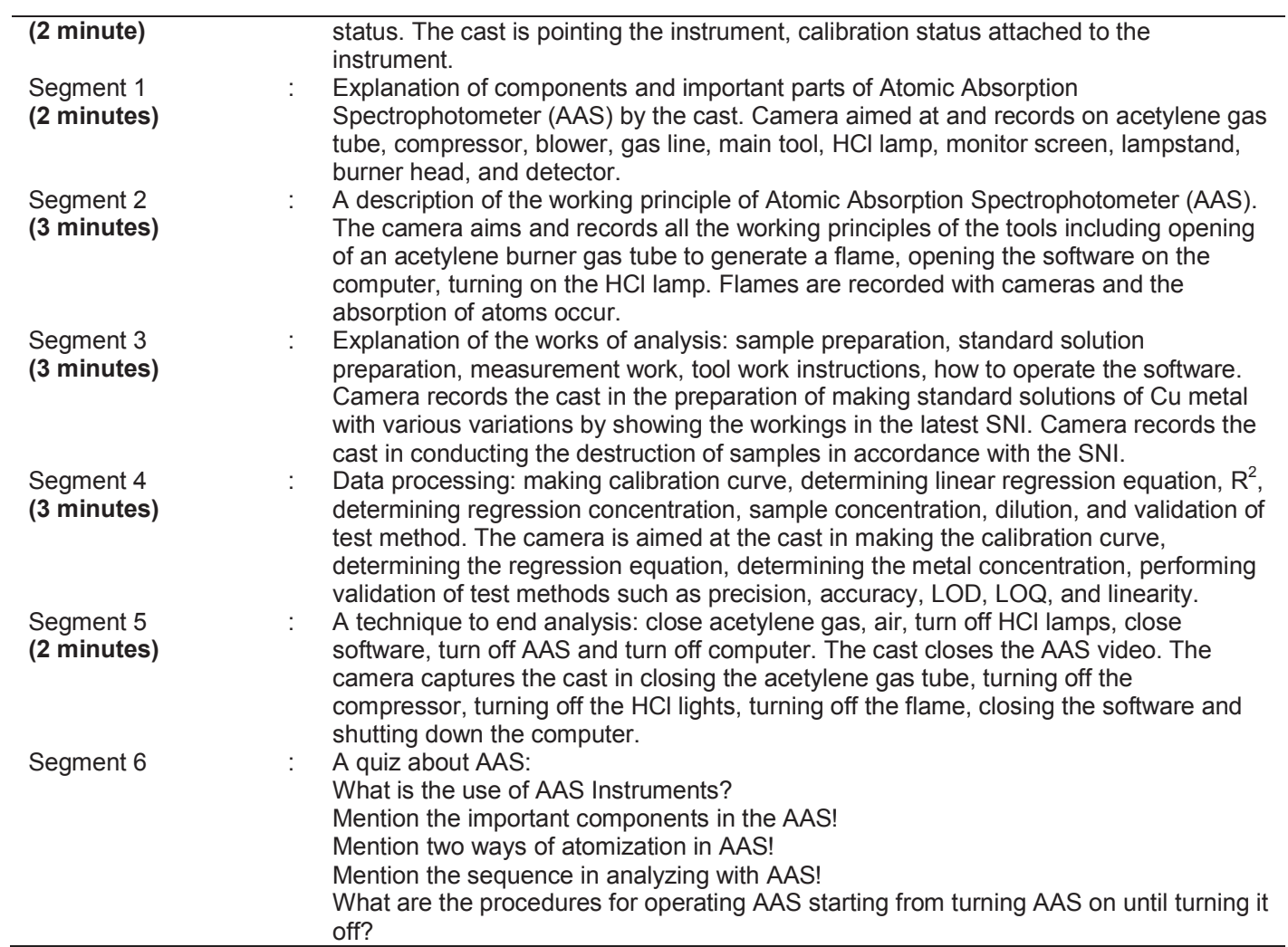

\section{RESULTS AND DISCUSSION}

The result of research shown in Table 2., Table 3. and Table 4.

\begin{tabular}{ccc} 
& \multicolumn{2}{c}{ TABLE 2. Sample Homogeneity Test } \\
\cline { 2 - 3 } & \multicolumn{2}{c}{ F-Test Two-Sample for Variances } \\
\cline { 2 - 3 } & Experiment Class & Control Class \\
\hline Mean & 78.6779661 & 75.38983051 \\
Variance & 155.2565751 & 168.5867914 \\
Observations & 59 & 59 \\
Df & 58 & 58 \\
F & 0.920929652 & \\
$\mathrm{P}(\mathrm{F}<=$ f) one-tail & 0.377418099 & \\
$\mathrm{~F}$ Critical one-tail & 0.946927499 & \\
\hline
\end{tabular}

Based on Table 2. F arithmetic $(0.9209)<\mathrm{F}$ table $(0.9469)$, then, both classes have the same or homogeneous variances

TABLE 3. T-Test result data: Two-Sample Assuming Equal Variances

\begin{tabular}{ccc}
\cline { 2 - 3 } & Experiment Class & Control Class \\
\hline Mean & 78.84745763 & 75.1 \\
Variance & 156.7177089 & 170.7694915 \\
Observations & 59 & 60 \\
Pooled Variance & 163.8036506 &
\end{tabular}




\begin{tabular}{ccc}
\cline { 2 - 3 } & Experiment Class & Control Class \\
\hline Hypothesized Mean Difference & 0 & \\
Df & 117 & \\
$\mathrm{t}$ Stat & 1.596993296 \\
$\mathrm{P}(\mathrm{T}<=\mathrm{t})$ one-tail & 0.05648232 \\
$\mathrm{t}$ Critical one-tail & 1.657981659 \\
$\mathrm{P}(\mathrm{T}<=\mathrm{t})$ two-tail & 0.11296464 \\
$\mathrm{t}$ Critical two-tail & 1.980447532 \\
\hline
\end{tabular}

Based on Table 3., it is showed that Ho: $\mu$ Experiment $=\mu$ Control and $\mathrm{H} 1$ : $\mu$ Experiments $>\mu$ Control, with $p$-value 0.056 , significant at $\alpha=0.05$. Then there is a significant difference in the mean of final scores between the experimental class and the control class. Based on the mean scores it is indicated that the VBL method is better when compared to the method without the VBL.

TABLE 4. Comparison of measurement results between the experimental class and the control class

\begin{tabular}{|c|c|c|c|}
\hline \multirow{2}{*}{ No. } & \multirow{2}{*}{ Indicator } & \multicolumn{2}{|c|}{ Realization } \\
\hline & & Experiment Class & Control Class \\
\hline \multirow{7}{*}{1.} & College students: & & \\
\hline & Level of student motivation & $100 \%$ & $94 \%$ \\
\hline & Student with score $\geq \mathrm{B}$ & $83 \%$ & $70 \%$ \\
\hline & Timeliness of attendance & $100 \%$ & $100 \%$ \\
\hline & Number of attendance 14 times & $36.67 \%$ & $20 \%$ \\
\hline & Score of Practicum $\geq B$ & $100 \%$ & $88 \%$ \\
\hline & Psychomotor Measurement Result & $100 \%$ & $100 \%$ \\
\hline \multirow{2}{*}{2.} & Lecturer: & & \\
\hline & Result on Students Assessment (scale 4) & 3.71 & 3.73 \\
\hline
\end{tabular}

The study used two different classes, one experimental class is given a VBL method, while the control class is a class that is not treated by the VBL method. Each class that is the experiment and the control class is 60 students. Because the research uses different classes then to determine the influence of VBL method, the test of data homogeneity must be hold. The data used in the research comes from the final score in the form of numbers. The final score is a combination of Final Semester Test, Mid-Semester Test, and tasks scores. The final score obtained then determined its homogeneity by using sample homogeneity test. The test results using Excel generated data in Table 2 that is the $F$ count $(0.9209)<F$ table (0.9469), then, both classes have the same or homogeneous variances. Because the data are homogeneous, it is continued by using the t-test in Table 3 to obtain $\mathrm{Ho}$ : $\mu$ Experiment $=\mu$ Control and $\mathrm{H} 1$ : $\mu$ Experiment $>\mu$ Control, with $p$-value 0.056 , significant at $\alpha=0.06$. Then there is a significant difference in the average of the final score between the experimental class and the control class. Based on the average of score indicates that the VBL method is better when compared to the method without the VBL.

The significant influence of the VBL method implementation is determined on student's motivation in following the Chemistry Instrumentation lecture. Almost $100 \%$ of respondents stated that students are motivated by the application of the VBL method. The application of VBL method is also can be seen from the increasing of psychomotor ability of students in instrumental chemistry practicum. The significant influence of the VBL method implementation is seen from the number of student attendance 14 times that is $36,67 \%$ while control class counted $20 \%$. In addition, the application of the VBL method has an impact on the Instrumental Chemistry Instrument Value Score $1 \geq B$ as much as $100 \%$, while the control class is only $88 \%$.

The results also pointed out that the application of the VBL method is lower than the control value, although the difference is not significant. This is due to many students feel bored with the video duration of 10-15 minutes. Therefore, to correct this problem, based on some research results the optimal time of video viewing is for 5 minutes. 


\section{CONCLUSION}

The results pointed out the data of both samples (two classes) is homogeneous. The result of the t-t est: Two-Sample Assuming Equal Variances shows that there is a significant difference of the average of final scores between the experimental class and the control class. Based on the mean scores indicate that the VBL method is better when compared to the method without the VBL.

The VBL method has a strong effect on student motivation and psychomotor ability viewed from observation of practicum and score of practicum. The conclusion is that the VBL method is able to increase students' motivation and psychomotor ability in Instrumental Chemistry subject.

\section{ACKNOWLEDGMENTS}

The researchers would like to thank Academic Developmental Board of UII for the aid of the research fund provided so that the research runs smoothly.

\section{REFERENCES}

1. Seng, 2009, W.C., Introduction to Problem-Based Learning (PBL), National Training Lab., Bethel, Maine, USA.

2. I. A. Richard, "Learning to Teach Sixth Edition" (Mc Grow Hill, United State, 2004).

3. S. N. Elliot, S. M. Sheridan and F. M. Gresham, JSP, 27, 2, $197-222$, .

4. T. David, L. Patel, K. Burdett and P. Rangachari, Med. Educ, 34, 4, 322 - 323, 2000.

5. H. S. Barrows, "Excerpt from Problem-Based Learning Applied to Medical Education", (The Royal Society of Medicine Press Limited, London, 2000).

6. A. Myers, J. Opt. Ed, 15, 4, 105-110, 1990.

7. B. Henriksen and A. Neppl, Curr. Pharm. Teach. Learn, 6, 3, $380-385,2014$.

8. H. T. Hou, Comput. Human. Behav, 48, $424-435,2015$.

9. P. L. Lei, C. T. Sun, S. S. J. Lin and T. K. Huang, Comput. Education, 87, 326-339, 2015.

10. K. Saiman, S. Sinnatamby, L. M. Mustafa, N. Alias and S. Siraj, Procedia - Social and Behavioral Sciences, 103, 459-466, 2013.

11. R. Peredo, A. Canales, A. Menchaca and I. Peredo, Expert. Syst. Appl, 38, 12, 14690-14702, 2011.

12. Z. Merchant, E. T. Goetz, L. Cifuentes, W. K. Kennicutt and T. J. Davis, T.J., 2014, Comput. Education, 70, 29-40, 2014.

13. J. Kuhn and A. Müller, Perspectives in Science, 2, 1-4, 5-21, 2014.

14. R. Kay and I. Kletskin, Comput. Education, 59, 2, 619-627, 2012.

15. B. Marsh, N. Mitchell and P. Adamczyk, Comput. Education, 54, 3, 742-748, 2010. 